\title{
Efeito protetor das frações proteicas do soro de leite em camundongos Balb/C infectados por Escherichia coli 0157:H7
}

[Protective effect of whey proteic fractions on Balb/c mice infected by Escherichia coli O157:H7]

\author{
J.P. Teixeira, N. Silva, L.M. Fonseca \\ Escola de Veterinária - UFMG \\ Av. Antônio Carlos, 6627 \\ 31270-901 - Belo Horizonte, MG
}

\begin{abstract}
RESUMO
Avaliou-se o efeito protetor das frações proteicas do soro do leite sobre as vilosidades intestinais de camundongos Balb/C, fêmeas, infectadas por Escherichia coli O157:H7. Foram utilizados 48 animais, distribuídos aleatoriamente em oito grupos de seis fêmeas cada um. Os animais dos grupos 1 e 2 (controles) receberam dieta AIN93G padrão; os dos grupos 3 e 4, AIN93G + alfalactalbumina; os dos grupos 5 e 6 , AIN93G + betalactoglobulina e os dos grupos 7 e 8, AIN93G + concentrado proteico total e água ad libitum por sete dias. No dia zero, os animais dos grupos 2, 4, 6 e 8 foram inoculados, por meio de cânula de gavagem, com 0,5mL de $E$. coli $\mathrm{O} 157: \mathrm{H} 7$, na concentração de 7 x $10^{10} \mathrm{UFC} / \mathrm{mL}$. Os animais foram acompanhados clinicamente e sacrificados, no oitavo dia experimental. Verificou-se, por meio de exames histológicos e da morfometria, que as frações betalactoglobulina e alfalactalbumina exerceram efeito protetor sobre as vilosidades intestinais do jejuno distal e do íleo $(\mathrm{P}<0,05)$, respectivamente. $\mathrm{O}$ concentrado proteico total não demonstrou efeito protetor sobre as vilosidades intestinais.
\end{abstract}

Palavras-chave: camundongo, alfalactalbumina, betalactoglobulina, vilosidade intestinal

\begin{abstract}
The protective effect of protein fractions of whey on intestinal villi of Balb/C female mice infected with Escherichia coli O157: H7 was evaluated. A total of 48 animals were randomly distributed into eight groups of six females each. Animals in groups 1 and 2 (controls) received AIN93G standard diet; the groups 3 and 4, AIN93G + alpha-lactalbumin; while groups 5 and 6, AIN93G + beta-lactoglobulin; and groups 7 and 8, AIN93G + total protein concentrate and water ad libitum for seven days. On day zero, animals of groups 2, 4, 6, and 8 were inoculated by gavage tube with 0.5mL of E. coli O157: H7 at a concentration of $7 \times 10^{10} \mathrm{CFU} / \mathrm{mL}$. The animals were clinically followed and sacrificed on the eighth day. It was verified by histological examination and morphometry that the beta-lactoglobulin and alphalactalbumin exerted a protective effect on the villi of the distal jejunum and ileum $(P<0.05)$, respectively. The total protein concentrate showed no protective effect on the villi.
\end{abstract}

Keywords: mice, alpha-lactalbumin, beta-lactoglobulin, intestinal villi

\section{INTRODUÇÃO}

O soro do leite é conhecido há décadas como um produto de alto valor nutritivo. Do ponto de vista nutricional, as proteínas presentes no soro são consideradas superiores às caseínas (predominantes na massa do queijo) em vários aspectos, por exemplo, na presença de aminoácidos similares aos do leite humano. Essas proteínas, por sua alta digestibilidade, são recomendadas para a formulação de produtos substitutos ou análogos do leite humano em fórmulas infantis (Sindayikengera e Shui, 2006). Aproximadamente $98 \%$ dos sólidos totais do soro são representados pelas proteínas e, dentre elas, estão a alfalactalbumina, a

Recebido em 11 de setembro de 2009

Aceito em 16 de julho e 2010

E-mail: junia_pacheco@yahoo.com.br 
betalactoglobulina, a albumina sérica e as imunoglobulinas, que podem ser utilizadas em formulações para dietas ou para ação imunomoduladora, antiviral, antioxidante, antihipertensiva, antitumoral e antibacteriana, tanto in vivo quanto in vitro (Wolber et al., 2005; Kume et al., 2006).

Entre os microrganismos envolvidos no processo de toxinfecção alimentar, destaca-se Escherichia coli $\mathrm{O} 157: \mathrm{H} 7$, por causar quadros de diarreia hemorrágica devido aos danos produzidos à mucosa intestinal pela ação de suas endotoxinas. A doença ocorre pela capacidade dessas bactérias em aderir e em colonizar as células epiteliais intestinais (Araújo e Giuglinano, 2001; Nagano et al., 2003). No Brasil, casos de toxinfecção alimentar causados por $E$. coli $0157: \mathrm{H} 7$ são frequentemente confundidos com ocorrências de surtos de gastrinterites causadas por outros coliformes (Doenças..., 2007).

O objetivo deste trabalho foi avaliar o efeito protetor das frações proteicas do soro de leite sobre as vilosidades intestinais de camundongos Balb/C inoculados com E. coli O157:H7.

\section{MATERIAL E MÉTODOS}

O projeto foi aprovado pelo Comitê de Ética em Experimentação Animal da UFMG, protocolo ${ }^{\circ}$ 120/2007. Foram utilizados camundongos $\mathrm{Balb} / \mathrm{C}$ fêmeas, pesando entre 8 e $13 \mathrm{~g}$ (fornecidos pelo biotério IC-BIO - Instituto de Ciências Biológicas - UFMG), distribuídos em grupos experimentais de acordo com as recomendações de Afwuape et al. (2004).

Utilizou-se, para a inoculação dos camundongos, a amostra ATCC 43895 Escherichia coli O157:H7 (cedida pela Fundação Oswaldo Cruz Rio de Janeiro), que, após testes morfotintoriais e bioquímicos, foi distribuída em alíquotas de $1 \mathrm{~mL}$ em caldo BHI (Difco Lab. - Detroit, EUA) com $20 \%$ de glicerol estéril e mantida a $-80^{\circ} \mathrm{C}$ até a sua utilização (Nagano et al., 2003; Gagnon et al., 2006). Para preparo do inóculo, a amostra descongelada foi plaqueada em ágar MacConkey Sorbitol (Difco), incubada a $37^{\circ} \mathrm{C}$ por $24 \mathrm{~h}$, transferida para $150 \mathrm{~mL}$ de caldo TSB (Difco) e reincubada a $37^{\circ} \mathrm{C}$ por mais $48 \mathrm{~h}$ (Marek et al., 2004). A cultura em caldo TSB foi colocada sob agitação a 70rpm (Shaker - New Brunswick Sci. - Edison-NJ, EUA), a $37^{\circ} \mathrm{C}$ por $20 \mathrm{~h}$ e, logo após, foi centrifugada a $2000 \mathrm{x}$ g por $10 \mathrm{~min}$ a $10^{\circ} \mathrm{C}$. O precipitado obtido foi submetido a dois lavados, seguidos de centrifugação, em $10 \mathrm{~mL}$ de PBS estéril, pH 7,4. Foram realizadas diluições decimais seriadas em água peptonada a $1 \%$, e a contagem das unidades formadoras de colônias (UFC) foi realizada em placas de ágar TSA (Difco) após a incubação a $37^{\circ} \mathrm{C}$ por 24 horas (Mckillip et al., 2000; Marek et al., 2004).

As proteínas utilizadas foram fornecidas pelos detentores da patente US 6,900,290 B2, de 31 de maio de 2005 (Fonseca e Bradley, 2005). A dieta padrão (AIN93G), para camundongos em crescimento, contém amido de milho, caseína, sacarose, óleo de soja, celulose, minerais, vitaminas, L-cistina, bitartarato de colina e antioxidante tert-butylhydroquinona (Reeves, 1997). A AIN93G foi modificada, substituindose a caseína por alfalactalbumina, betalactoglobulina e concentrado proteico total (WPC), obedecendo à mesma concentração e proporção (Belobrajdic et al., 2003; Kume et al., 2006).

Antes da formação dos grupos experimentais (dias -3, -2, -1), coletaram-se fezes de todos os animais, as quais, após diluições decimais, foram inoculadas em ágar MacConkey Sorbitol (Difco). Utilizaram-se 48 camundongos, que não apresentaram colônias sorbitol negativas, distribuídos aleatoriamente em oito grupos experimentais de seis fêmeas cada um. Os animais dos grupos 1 e 2 (controles) receberam dieta AIN93G; os dos grupos 3 e 4, AIN93G + alfalactalbumina; os dos grupos 5 e 6 , AIN93G + beta-lactoglobulina e os dos grupos 7 e 8 , AIN93G + WPC. Os animais foram mantidos, em gaiolas apropriadas com acesso livre à água, por sete dias. No dia zero, após ficarem $12 \mathrm{~h}$ sem alimentação, os animais dos grupos 2, 4, 6 e 8 foram inoculados, por meio de cânula de gavagem, com $0,5 \mathrm{~mL}$ de $E$. coli $\mathrm{O} 157$ : $\mathrm{H} 7$, na concentração de $7 \times 10^{10} \mathrm{UFC} / \mathrm{mL}$ (Nagano et al., 2003; Afuwape et al., 2004). No dia 8, os animais foram sacrificados por deslocamento cervical de acordo com as recomendações do GPPG/HCPA (Utilização..., 1997) e necropsiados.

Para verificar as possíveis alterações causadas por E. coli O157:H7 na mucosa intestinal, amostras de segmentos do jejuno proximal, do jejuno distal, do íleo e do cólon foram retiradas 
(Dean-Nystron et al., 2003; Nagano et al., 2003). As amostras foram lavadas em solução de PBS, fixadas em formol tamponado $10 \%$, incluídas em parafina e cortadas em micrótomo (SpencerAmerican Optical - New York, EUA). Os cortes, com $5 \mu \mathrm{m}$ de espessura, foram montados em lâminas de vidro, corados com hematoxilina e eosina (HE). As análises histológicas e morfométricas foram feitas em microscópio óptico Zeiss acoplado a videocâmera. As imagens capturadas foram armazenadas em computador e analisadas pelo programa ImagePro ${ }^{\circledR}$ Plus (Media Cybernetics - Bethesda, EUA). À necropsia, foram também retirados fragmentos do baço, fígado e rins (Nagano et al., 2003).

O delineamento experimental foi o inteiramente ao acaso. As imagens da morfometria foram capturadas com o auxílio do programa ImagePro ${ }^{\circledR}$ Plus. Cada fragmento foi mensurado em cinco pontos diferentes, e a média desses valores foi considerada como resultado final da morfometria. Os resultados das alturas das vilosidades foram tabulados e analisados pelos testes estatísticos com o auxílio do software GraphPad Prism 3.0.3 (Graphpad Software Inc San Diego, EUA). Para comparar os dados referentes à altura das vilosidades intestinais entre os grupos-controle e os grupos inoculados, foi utilizada a técnica de pareamento por meio do teste t-Student. Foram comparados grupo $1 \mathrm{com}$ grupo 2; grupo $3 \mathrm{com}$ grupo 4; grupo $5 \mathrm{com}$ grupo 6; grupo 7 com grupo 8. Os dados foram considerados significativos quando apresentaram $\mathrm{P}<0,05$. Para comparar os dados referentes à altura das vilosidades intestinais entre todos os grupos, utilizou-se o teste Anova one-way com análise de variância e teste de comparação múltipla, segundo Tukey. Os dados foram considerados significativos quando apresentaram $\mathrm{P}<0$,05. (Sampaio, 2002; Wolber et al., 2005).

\section{RESULTADOS E DISCUSSÃO}

Observou-se que o tratamento prévio dos camundongos com estreptomicina na água, durante 24h, para diminuir a microbiota bacteriana do intestino, possibilitou a utilização desses animais. Os animais experimentais inoculados com E. coli O157:H7 não apresentaram evacuação aquosa (diarreia) ou com sangue, o que também foi observado por Nagano et al. (2003). Observou-se apenas que alguns animais do grupo 4 apresentaram fraqueza nos membros posteriores e dificuldade de locomoção. Esses animais também apresentaram uma contagem de UFC/g de fezes, no ágar sorbitol, maior no dia sete após o desafio (dados não mostrados). Cerca de 20 a $30 \%$ dos pacientes infectados por E. coli $\mathrm{O} 157: \mathrm{H} 7$ podem apresentar encefalopatia, que é uma complicação que afeta o sistema nervoso central, sendo grande determinante de mortandade na fase aguda da infecção. Segundo Taguchi et al. (2002), camundongos infectados experimentalmente com E. coli EHEC desenvolvem sintomas neurológicos e sistêmicos. Os sintomas neurológicos, nas encefalopatias, podem ser induzidos por toxinas bacterianas, as quais inibem a síntese proteica das células eucarióticas, incluindo as células endoteliais do cérebro. Mais especificamente, as toxinas tipo shiga II, que são tóxicas também para os neurônios do sistema nervoso central, causam encefalopatia fatal aguda. Neste estudo, apesar de não ter sido feita a avaliação histológica do cérebro, pode-se deduzir, ou suspeitar, que os distúrbios de equilíbrio parecem ter sido causados por algum tipo de encefalopatia. Em alguns animais dos grupos inoculados com E. coli O157:H7, observaram-se letargia e eriçamento de pelos, após o terceiro dia experimental.

Alterações histológicas e morfométricas foram observadas nos segmentos intestinais avaliados; algumas alterações mais aparentes na altura das vilosidades das porções dos jejunos distais e dos íleos foram avaliadas separadamente por morfometria (Fig. 1 e 2).

$\mathrm{Na}$ comparação múltipla entre os grupos de animais inoculados, observou-se que os animais tratados com a fração alfalactalbumina (grupo 4) apresentaram maior integridade das vilosidades (Fig. 1). Os animais dos grupos 2, 6 e 8 (inoculados com E. coli $\mathrm{O} 157: \mathrm{H} 7$ ) apresentaram vilosidades de jejuno distal irregulares e não diferiram do grupo-controle (grupo 2), semelhante ao resultado obtido por Gagnon et al. (2006). A bactéria, por ser ácido resistente, atravessa o estômago e fixa-se na região mais distal do intestino delgado (Dean Nystron et al., 2003). Nesse local, as placas de Peyer estão em maior número e a motilidade intestinal é reduzida pela válvula ileocecal, o que propicia à bactéria maior tempo para colonizar e causar danos (Phillips et al., 2000). 
Em relação às vilosidades ileais, detectou-se diferença significativa $(\mathrm{P}<0,05)$ no grupo $6 \mathrm{em}$ relação aos demais grupos de tratamento (Fig. 2).
Verificou-se, portanto, que o tratamento com betalactoglobulina apresentou o maior efeito protetor para as vilosidades do íleo.

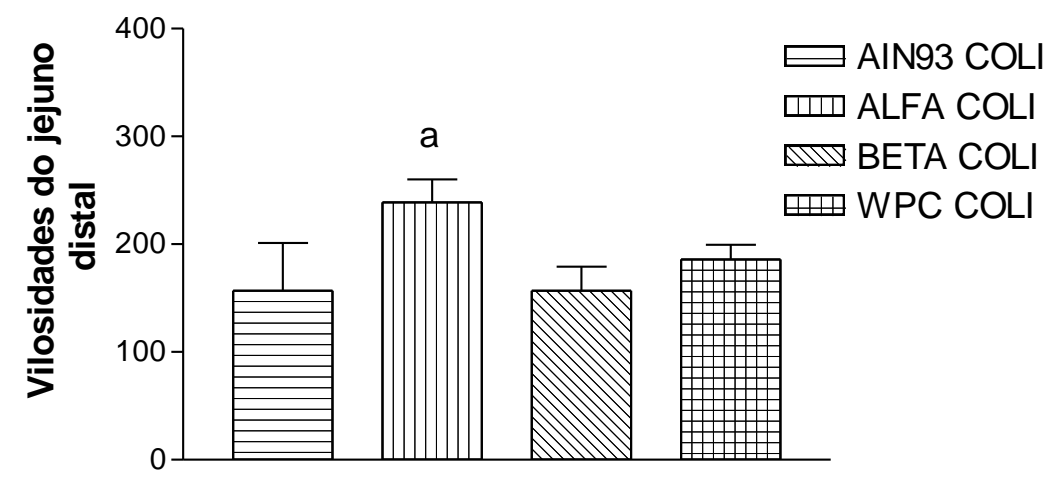

Figura 1. Altura das vilosidades do jejuno distal (micrômetro) dos camundongos tratados com as frações proteicas do soro de leite (alfalactalbumina, betalactoglobulina e concentrado proteico total - WPC) e inoculados com E. coli $\mathrm{O} 157: \mathrm{H} 7$. As medições foram feitas em quintuplicata, sete dias após a inoculação. $\perp$ : desvio-padrão; a: diferença significativa, $\mathrm{P}=0,00$.

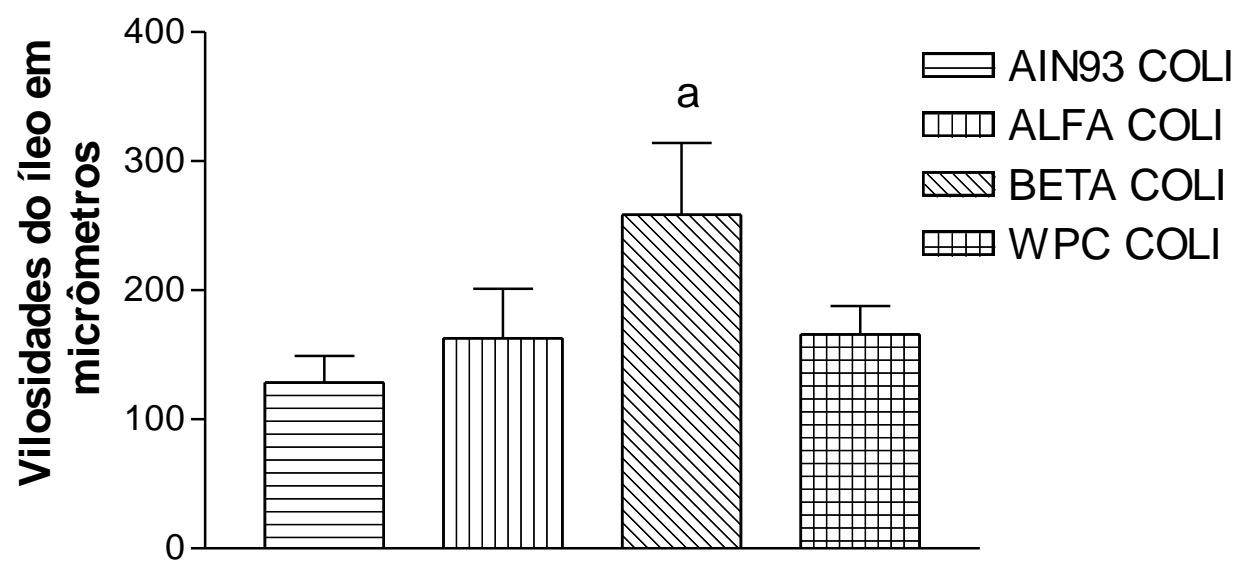

Figura 2. Altura das vilosidades ileais de camundongos tratados com as frações proteicas do soro de leite (alfalactalbumina, betalactoglobulina e concentrado proteico total - WPC) e inoculados com E. coli O157:H7. As medições foram feitas em quintuplicata, sete dias após a inoculação. $\perp$ : desvio-padrão; a: diferença significativa, $\mathrm{P}=0,00$.

O achatamento ou desaparecimento das vilosidades podem ser resultantes da despolimerização da actina desencadeada pela ação das toxinas da bactéria aderente (E. coli O157:H7), o que impede a ação de reconstrução das vilosidades (Vallance e Finlay, 2000). Segundo Nagano et al. (2003), nutrição proteicocalórica inadequada pode aumentar a susceptibilidade a EHEC O157:H7 em camundongos. Assim, com base na imunidade de mucosa, a betalactoglobulina e a alfalactalbumina e seus peptídeos associados fornecem alta proporção de cisteína, a qual é requerida para a síntese de proteínas envolvidas nas respostas de fase aguda. O conteúdo de cisteína utilizado na síntese de glutationa, em combinação com lisozima, outro elemento que pode ser isolado do soro de leite, promove integração de fatores aparentemente sinérgicos que protegem contra organismos virais e bacterianos. Além disso, tais proteínas são ricas em aminoácidos sulfurados, utilizadas como 
suplemento proteico em dietas para melhoria do sistema imune, e agem, principalmente, no tecido linfoide associado ao intestino ou sistema GALT (Low et al., 2003). As interações entre os elementos do leite e a bactéria ocorrem prevenindo as lesões nas células epiteliais (Araújo e Giuglinano, 2001) e melhorando o mecanismo de defesa inata do hospedeiro às infecções (Afuwape et al., 2004). Não foram evidenciados danos causados por E. coli O157:H7 no baço, no fígado e nos rins.

\section{CONCLUSÕES}

As frações proteicas do soro, alfalactalbumina e betalactoglobulina, exercem efeito protetor sobre as vilosidades intestinais do jejuno distal e do íleo em camundongos Balb/C inoculados com $E$. coli $\mathrm{O} 157: \mathrm{H7}$.

\section{REFERÊNCIAS BIBLIOGRÁFICAS}

AFUWAPE, A.O.; TURNER, M.W.; STROBEL, S. Oral administration of bovine whey proteins to mice elicits opposing immunoregulatory responses and is adjuvant dependent. Clin. Exp. Immunol., v.136, p.40-48, 2004.

ARAÚJO, A.N.; GIUGLIANO, L.G. Lactoferrin and free secretory component of human milk inhibit the adhesion of enteropathogenic E. coli O157: H7 to HeLa cells. BMC Microbiol., v.1, 1421-2180, 2001.

BELOBRAJDIC, D.P.; McINTOSH, G.H.; OWENS, J.A. Whey proteins protect more than red meat against azoxymethane induced ACF in wistar rats. Cancer Lett., v.198, p.43-51, 2003.

DEAN-NYSTRON, E.A.; MELTON-CELSA, A.R.; POHLENZ, J.F.L. et al. Comparative pathogenicity of Escherichia coli $\mathrm{O} 157$ and intimin-negative non-O157 shiga toxinproducing $E$. coli strains in neonatal pigs. Infect. Immun., v.71, p.6526-6533, 2003.

DOENÇAS transmitidas por alimentos. São Paulo; Centro de Vigilância Epidemiológica, Secretaria de Saúde do Estado de São Paulo, 2007. (informe Net DTA) Disponível em: <http://www.cve.saude.sp.gov.br/htm/hidrica/Ec olinet.htm//>. Acessado em: $18 \mathrm{dez} .2007$.
FONSECA, L.M.; BRADLEY, J.R. Fractionation of whey proteins by complex formation. Patente $\mathrm{n}^{\circ}$ US 6,900,290 B2. Madison: Winsconsin Alumni Research Foundation, 2005. p.1-24.

GAGNON, M.; KHEADR E. E.; DABOUR, N.; RICHARD, D.; FLISS, I. Effect of Bifidobacterium thermacidophilum probiotic feeding on enterohemorrhagic Escherichia coli O157: H7 infection in Balb/C mice. Int. J. Food Microbiol., v.111, p.26-33, 2006.

KUME, H.; OKASAKI, K.; SASAKI, H. Hepatoprotective effects of whey on Dgalalactosamine- induced hepatitis and liver fibrosis in rats. Biosc. Biotech. Biochem., v.70, p.1281-1285, 2006.

LOW, P.P.L.; RUTHERFURD, K.J.; GILL, H.S. et al. Effect of dietary whey protein concentrate on primary and secondary antibody responses in immunized $\mathrm{Balb} / \mathrm{C}$ mice. Int. Immunopharmacol., v.1, p.393-401, 2003.

MAREK, P.; NAIR, M.K.M.; HOAGLAND, T. et al. Survival and growth characteristics of Escherichia coli O157: H7 in pasteurized and unpasteurized cheddar cheese whey. Int. J. Food Microbiol., v.94, p.1-7, 2004.

MCKILLIP, J.L.; JAYKUS, L.A.; DRAKE, M.A. A comparison of methods for the detection of Escherichia coli $\mathrm{O} 157: \mathrm{H} 7$ from artificiallycontaminated dairy products using PCR. J. Appl. Microbiol., v.89, p.49-55, 2000.

NAGANO, K.; TAGUCHI, K.; HARA, T. et al. Adhesion and colonization of enterohemorrhagic Escherichia coli O157:H7 in cecum of mice. Microbiol. Immunol., v.47, p.125-132, 2003.

PHILLIPS, A.D.; NAVABPOUR, S.; HICKS, S. et al. Enterohaemorragic Escherichia coli O157:H7 target Peyer's patches in humans and cause attaching/effacing lesions in both human and bovine intestine. Gut, v.47, p.377-381, 2000.

REEVES, P.G. Components of the AIN-93 diets as improvements in the AIN-76A diet. J. Nutr., v.127, p.838-841, 1997.

SAMPAIO, I.B.M., Estatística aplicada à experimentação animal. 2.ed. Belo Horizonte: FEPMVZ, 2002. 265p. 
SINDAYIKENGERA， S.; WWN-SHUI， W. Nutritional evaluation of caseins and whey proteins and their hydrolysates from protamex. $J$. Zhejiang Univ. Sci. B, v.7, p.90-98, 2006.

TAGUCHI, H.; TAKAHASHI, M.; YAMAGUCHI, H. et al. Experimental infection of germ-free mice with hyper-toxigenic enterohaemorragic Escherichia coli O157:H7, strain 6. J. Med. Microbiol., v.51, p.336-343, 2002.

UTILIZAÇÃO de animais em projetos de pesquisa. Resolução Normativa 04/97. Comissão de Pesquisa e Ética em Saúde/GPPG/HCPA, $1997 . \quad$ Disponível em: <http://www.ufrgs.br/bioetica/res497hc.htm>. Acessado em: 6 set. 2006.
VALLANCE, B.A.; FINLAY, B.B. Exploitation of host cells by enteropathogenic Escherichia coli. Proc. Natl. Acad. Sci., v.97, p.8799-8806, 2000.

WOLBER, F.M.; BROOMFIELD, A.M.; FRAY, L. et al. Supplemental dietary whey protein concentrate reduces rotavirus-induced disease symptoms in suckling mice. J. Nutr., v.135, p.1470-1474, 2005 